\title{
A Cadaveric Case of a Circular Torcular Herophili
}

\author{
Sasha Lake ${ }^{1}$, Juan J. Altafulla ${ }^{2}$, Joe Iwanaga ${ }^{3}$, Rod J. Oskouian ${ }^{4}$, Marios Loukas ${ }^{5}$, R. Shane Tubbs ${ }^{6}$ \\ 1. Anatomical Studies, St. George's, St. George, GRD 2. SNI, Seattle Science Foundation, Seattle, USA 3. Medical \\ Education and Simulation, Seattle Science Foundation, Seattle, USA 4. Neurosurgery, Swedish Neuroscience Institute, \\ Seattle, USA 5. Anatomical Sciences, St. George's University, St. George's, GRD 6. Neurosurgery, Seattle Science \\ Foundation, Seattle, USA
}

Corresponding author: Joe Iwanaga, iwanagajoeca@gmail.com

\begin{abstract}
The torcular Herophili is formed by the joining of the straight sinus, superior sagittal sinus, and transverse sinus. The anatomic configuration of the torcular Herophili is highly variable. In the current literature, classification systems define up to nine subtypes of the torcular Herophili. The frequency of prevalence of these anatomical variants is also variable. Herein is a case report of a circularly-shaped torcular Herophili found during cadaveric dissection.
\end{abstract}

Categories: Neurology, Pathology, Neurosurgery

Keywords: waiting, torcular herophili, confluence sinus, torcular morphology, torcular variants

\section{Introduction}

The confluence of sinuses also called the torcular Herophili lies near the internal occipital protuberance and receives venous drainage from various regional dural venous sinuses [1]. Classically, the torcular forms at the convergence of the superior sagittal, straight, and transverse sinuses. However, the anatomical morphology of the torcular is highly variable, and the classification systems thus far describe nine subtypes of torcular morphology. The classical form of the torcular represents the most common subtype [2-3]. Other subtypes are under-reported throughout the literature and can have clinical/surgical implications [4].

\section{Case Presentation}

During the routine dissection of an adult male cadaver aged 87 years at death, an unusual arrangement of the dural venous sinuses was identified (Figure 1). This specimen had previously undergone blue latex injection of the intracranial venous system. Posteriorly, the region overlying the internal occipital protuberance was found to be encircled by a splitting of the superior sagittal sinus above into two more or less equal parts each draining into one of the transverse sinuses. Additionally, there was a midline connection between the left and right transverse sinuses, effectively forming a venous circle around the internal occipital protuberance, i.e., a circular torcular Herophili. No other neurovascular variations were identified in this specimen.

Received 07/31/2018

Review began 08/02/2018 Review ended 08/02/2018 Published 08/04/2018

() Copyright 2018

Lake et al. This is an open access article distributed under the terms of the Creative Commons Attribution License CC-BY 3.0., which permits unrestricted use, distribution, and reproduction in any medium, provided the original author and source are credited.

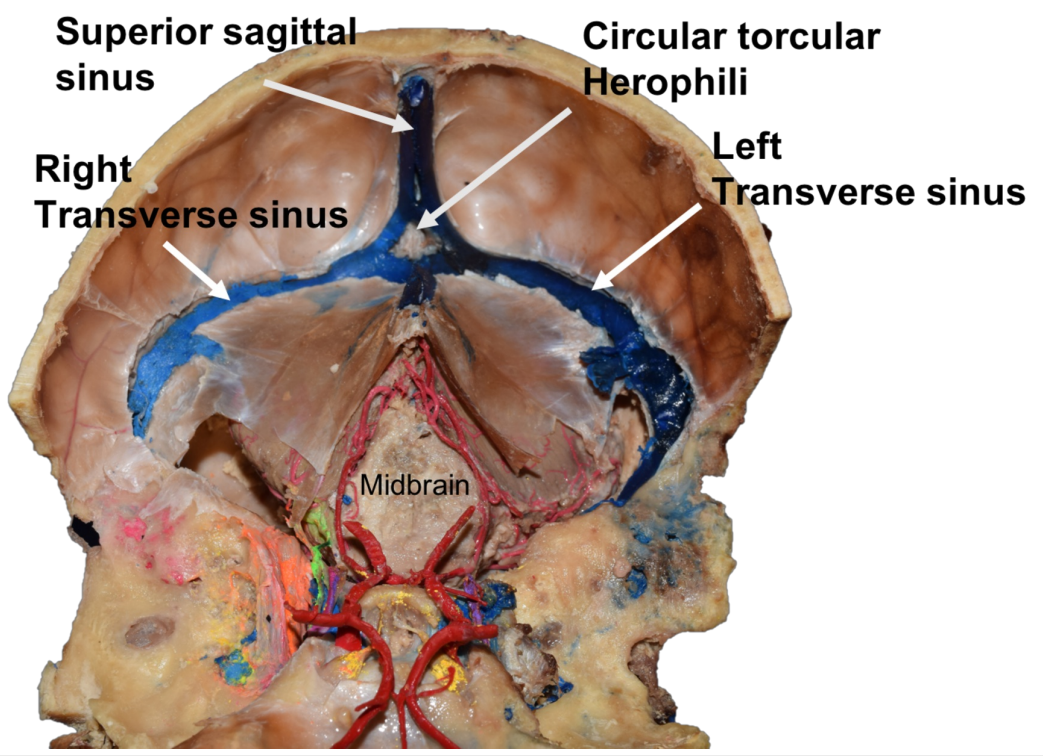

FIGURE 1: Internal view of the case presented herein

Note the circular torcular Herophili and its relationship to the transverse and superior sagittal sinuses. 


\section{Discussion}

Recently, Matsuda et al. reexamined anatomical variations of the torcular, focusing on venous flow and the continuity of the superior sagittal and transverse sinuses. They reported that venous flow from the superior sagittal sinus to the transverse sinus could be either symmetric or asymmetric [5]. The findings of the Matsuda et al. study added to the literature compilation that established venous drainage at the torcular as symmetric or asymmetric [1-2,4,6-7]. Despite the asymmetry of venous flow, on venography, the torcular usually forms an inverted $\mathrm{T}$ shape-with the superior sagittal sinus representing free communication between the superior sagittal, the straight, the occipital, and the transverse sinuses [6]. The inverted $\mathrm{T}$ shape accurately describes the traditional anatomy and the most common depiction of the torcular [3]. However, the literature also reported many anatomical variations of the torcular $[1-3,5-6,8]$. Kobayashi et al. elaborately classified nine types of variants of the torcular. Their study further classed communications between the right and left transverse sinus into four subtypes [3].

Recently, a circular variant of the torcular was reported on magnetic resonance imaging from a patient suffering from chronic headaches and questionable papilledema [4]. In the present case, a similar finding was seen in a cadaveric dissection. Another interpretation of the present case could also be a splitting of the superior sagittal sinus into left and right parts that travel to the left and right transverse sinuses, respectively. This, coupled with a communication across the midline of the left and right transverse sinuses, resulted in a circular configuration in the region of the torcular. The development of the torcular occurs during the fourth to sixth months of gestation [8-10]. A series of transitional growth and regression patterns of primitive dural plexuses to dural sinuses occurs during this period. Irregular patterns of growth can lead to different heights and size asymmetry of the dural sinuses, mild to marked irregularities, or even an absence of the medial portion of the transverse sinuses [8].

\section{Conclusions}

The embryology of the dural sinuses further elucidates the genesis of anatomical variants. The torcular Herophili is an area of interest for neurosurgical and interventional procedures. Given the high variability of the region, an awareness of normal anatomy and variations such as seen in the case presented herein is crucial for preoperative planning and during the interpretation of cranial imaging.

\section{Additional Information}

\section{Disclosures}

Human subjects: All authors have confirmed that this study did not involve human participants or tissue. Conflicts of interest: In compliance with the ICMJE uniform disclosure form, all authors declare the following: Payment/services info: All authors have declared that no financial support was received from any organization for the submitted work. Financial relationships: All authors have declared that they have no financial relationships at present or within the previous three years with any organizations that might have an interest in the submitted work. Other relationships: All authors have declared that there are no other relationships or activities that could appear to have influenced the submitted work.

\section{References}

1. Bisaria KK: Anatomic variations sinuses in the region of the torcular Herophili . J Neurosurg. 1985, 62:90-95. 10.3171/jns.1985.62.1.0090

2. Kaplan HA, Browder J, Knightly JJ, Rush BF, Browder A: Variations of the cerebral dural sinuses at the torcular Herophili. Importance in radical neck dissection. Am J Surg. 1972, 124:456-461. 10.1016/0002 9610(72)90066-9

3. Kobayashi K, Matsui O, Suzuki M, Ueda F: Anatomical study of the confluence of the sinuses with contrastenhanced magnetic resonance venography. Neuroradiology. 2006, 48:307-311. 10.1007/s00234-006-0065-4

4. Tardieu GG, Oskouian RJ, Loukas M, Tubbs RS: A previously undescribed variant of the confluence of sciences. Folia Morphol. 2016, 76:316-318. 10.5603/FM.a2016.0063

5. Matsuda W, Sonomura T, Honma S, et al.: Anatomical variations of the torcular Herophili: macroscopic study and clinical aspects. Anat Sci Int. 2018, 93:464-468. 10.1007/s12565-018-0436-Z

6. Segal RS, Rosenberg HK: Sonographic appearance of the torcular Herophili. AJR Am J Roentgenol. 1986, 6:109-112. 10.2214/ajr.146.1.109

7. Singh M, Nagashima M, Inoue Y: Anatomical variation of occipital bone impressions for dural venous sinuses around the torcular Herophili, with special reference to the consideration of clinical significance. Surg Radiol Anat. 2007, 26:480-487.

8. Widjaja E, Griffin PD: Intracranial MR venography in children: normal anatomy and variations . AJNR Am J Neuroradiol. 2004, 25:1557-1562.

9. Shoja MM, Ramdhan R, Jensen CJ, Chern JJ, Oakes WJ, Tubbs RS: Embryology of the craniocervical junction and posterior cranial fossa, part I: development of the upper vertebrae and skull. Clin Anat. 2018, 31:466487. 10.1002/ca.23049

10. Shoja MM, Ramdhan R, Jensen CJ, Chern JJ, Oakes WJ, Tubbs RS: Embryology of the craniocervical junction and posterior cranial fossa, part II: embryogenesis of the hind brain. Clin Anat. 2018, 31:488-500. 


\section{Cureus}

10.1002/ca.23048 